\title{
Dexmedetomidine reduces ventilator-induced lung injury via ERK1/2 pathway activation
}

\author{
CHUN-HUA ZHU, JIAN YU, BEN-QING WANG, YU NIE, LEI WANG and SHI-QIANG SHAN \\ Department of Anesthesiology, Cangzhou Central Hospital, Cangzhou, Hebei 061000, P.R. China
}

Received January 22, 2020; Accepted September 15, 2020

DOI: $10.3892 / \mathrm{mmr} .2020 .11612$

\begin{abstract}
Mechanical ventilation (MV) can contribute to ventilator-induced lung injury (VILI); dexmedetomidine (Dex) treatment attenuates MV-related pulmonary inflammation, but the mechanisms remain unclear. Therefore, the present study aimed to explore the protective effect and the possible molecular mechanisms of Dex in a VILI rodent model. Adult male Sprague-Dawley rats were randomly assigned to one of seven groups ( $n=24$ rats/group). Rats were euthanized after $4 \mathrm{~h}$ of continuous $\mathrm{MV}$, and pathological changes, lung wet/dry (W/D) weight ratio, the levels of inflammatory cytokines (IL-1 $\beta$, TNF- $\alpha$ and IL-6) in the bronchoalveolar lavage fluid (BALF), and the expression levels of $\mathrm{Bcl}-2$ homologous antagonist/killer (Bak), Bcl-2, pro-caspase-3, cleaved caspase-3 and the phosphorylation of ERK1/2 in the lung tissues were measured. Propidium iodide uptake and TUNEL staining were used to detect epithelial cell death. The Dex pretreatment group exhibited fewer pathological changes, lower W/D ratios and lower expression levels of inflammatory cytokines in BALF compared with the VILI group. Dex significantly attenuated the ratio of $\mathrm{Bak} / \mathrm{Bcl}-2$, cleaved caspase-3 expression levels and epithelial cell death, and increased the expression of phosphorylated ERK1/2. The protective effects of Dex could be partially reversed by PD98059, which is a mitogen-activated protein kinase (upstream of ERK1/2) inhibitor. Overall, dexmedetomidine was found to reduce the inflammatory response and epithelial cell death caused by VILI, via the activation of the ERK1/2 signaling pathway.
\end{abstract}

\section{Introduction}

As an effective mode of treatment for acute respiratory distress syndrome (ARDS), mechanical ventilation (MV) is widely performed in patients under general anesthesia (1). However, certain MV strategies can result in

Correspondence to: Dr Shi-Qiang Shan, Department of Anesthesiology, Cangzhou Central Hospital, 16 Xinhua West Road, Yunhe, Cangzhou, Hebei 061000, P.R. China

E-mail: 15903175270@163.com

Key words: dexmedetomidine, ventilator-induced lung injury, ERK1/2 ventilator-associated complications, such as ventilator-induced lung injury (VILI) (2-4). In addition to mechanical damage, there is growing evidence that upregulation of inflammatory molecules, chemokines, leukocyte sequestration and excessive inflammatory responses has a vital role in the generation and progression of VILI (5-7). However, the definite mechanism through which this pro-inflammatory response is initiated and sustained, and how to relieve it, remain unclear.

Recently, it was reported that dexmedetomidine (Dex) exhibits analgesic and sedative properties for systemic anesthesia by intravenous (i.v.) infusion through the activation of $\alpha 2$ adrenergic receptors (8). In patients subjected to MV, Dex has been widely used in intensive care units. Ample evidence has been reported on the protective effects of MV on organs (9). It has been demonstrated that Dex could ameliorate VILI-induced pulmonary inflammation in animal models $(10,11)$; Chen et al (12) observed that dex reduces VILI induced inflammation by inhibiting TLR4 and NF- $\kappa \mathrm{B}$ signaling through $\alpha 2$-adrenoreceptors. However, the exact mechanism has yet to be established. It was hypothesized that the protective signaling pathways in the lung cells are initiated through Dex for the prevention of cellular apoptosis or necrosis when subjected to MV.

ERK $1 / 2$ is a member of the MAPK family, and serves a key role in the regulation of cell death and survival (13-15). The inhibition of ERK1/2 signaling induces the activation of apoptosis-associated proteins, such as $\mathrm{BH} 3$-interacting domain death agonist, Bcl-2-like protein 11 and p53 upregulated modulator of apoptosis. In addition, the MEK1/2-ERK1/2 signaling pathway may be involved in modulating the inflammatory response to lung injury and infection (16). However, little attention has been dedicated to the effects of Dex administration with respect to ERK1/2 and the expression of caspase-3, Bcl-2 and Bcl-2 homologous antagonist/killer (Bak) in VILI. Therefore, the present study aimed to provide evidence that supports Dex as a treatment against VILI in a rat model of high-tidal volume MV (HVT-MV) and to investigate the roles of phosphorylated (p)-ERK1/2.

\section{Materials and methods}

Animals. A total of 168 adult male Sprague-Dawley rats (6-8 weeks old, 200-250 g) were purchased from Liaoning Changsheng Biotechnology and housed one per cage at a stable temperature of $25 \pm 1^{\circ} \mathrm{C}$ with alternating 12-h light/dark cycle. Rats were allowed access to food and water ad libitum until the start of the experiments. All study procedures and 
animal handling were approved by the Animal Review Board of Cangzhou Central Hospital (Cangzhou, China) and were in accordance with the National Institutes of Health guidelines.

Group assignment and experimental protocol. After successful sevoflurane anesthesia (5\% for induction; $1.5-2.5 \%$ for maintenance), an indwelling needle $(22 \mathrm{G})$ was placed into the catheterized caudal (tail) vein. The left femoral artery was cannulated with a heparinized tube to monitor arterial blood pressure. The level of sevoflurane was adjusted to maintain stable hemodynamics. According to computer-based randomization, the rats were assigned to one of the following seven groups: i) Sham; ii) VILI; iii) VILI+low dose (L)-Dex; iv) VILI+high dose (H)-Dex; v) VILI+L-Dex+PD98059 (PD; Calbiochem; Merck $\mathrm{KGaA}$ ); vi) VILI+H-Dex+PD; and vii) PD only group. In the Sham group, rats were anesthetized with sevoflurane and kept on spontaneous breathing without MV for $4 \mathrm{~h}$, and IV catheterization was performed. In the VILI group, the endotracheal intubation tube was connected to a ventilator (model 683 Ventilator; Harvard Apparatus) for $4 \mathrm{~h}$. MV with a high tidal volume of $20 \mathrm{ml} / \mathrm{kg}$, respiratory frequency of $50 \mathrm{bpm}$, and compressed air was used. Each rat could achieve a peak airway pressure of $\sim 40 \mathrm{~cm} \mathrm{H}_{2} \mathrm{O}$, as measured by an Exactus II pressure gauge (Omron Healthcare Inc.). VILI+L-Dex group rats received the same MV strategy as those in the VILI group and received i.v. administration of a loading dose of Dex (Jiangsu Hengrui Medicine Co., Ltd.) of $1 \mu \mathrm{g} / \mathrm{kg}$ over $15 \mathrm{~min}$ before $\mathrm{MV}$, followed by a maintenance dose of $1 \mu \mathrm{g} / \mathrm{kg} / \mathrm{h}$ (i.v.) during MV. Similarly, rats in the VILI+H-Dex group received the same MV strategy and received i.v. administration of $10 \mu \mathrm{g} / \mathrm{kg}$ for loading dose and $10 \mu \mathrm{g} / \mathrm{kg} / \mathrm{h}$ for maintenance dose $(17,18)$. Rats in the VILI+L-Dex+PD group and the VILI+H-Dex+PD received subcutaneous injections of $1 \mathrm{mg} / \mathrm{kg}$ PD, an ERK1/2 inhibitor (19,20), $30 \mathrm{~min}$ prior to MV and Dex infusion. The dose of $1 \mathrm{mg} / \mathrm{kg}$ was based on a preliminary experiment and a previous study (21). Subsequently, the ventilation strategy of the rats and the infusion of Dex were consistent with the VILI+L-Dex group and the VILI+H-Dex groups. Finally, rats in the PD group received $1 \mathrm{mg} / \mathrm{kg}$ PD subcutaneously.

At the end of each experiment, the lungs and bronchoalveolar lavage fluid (BALF) were collected under anesthesia with sevoflurane. The left lung lobe was used for determining the lung wet/dry (W/D) weight ratio after removing the blood and water from the lung surface.

Histopathological analysis. After fixing in $4 \%$ paraformaldehyde at room temperature overnight, the lung tissues were dehydrated and embedded in paraffin. The tissue sections (thickness, $4 \mu \mathrm{m}$ ) were stained with hematoxylin and eosin $(\mathrm{H} \& \mathrm{E})$. The images were captured under a light microscope and then assessed by a pathologist who was blinded to the groups. Each sample was evaluated according to the following three criteria: i) Alveolar edema; 0 , no edema in the interstitium; 1 , slight edema in the interstitium wit hyaline membrane formation; 2 , interstitial edema is evident; 3 , interstitial edema is further aggravated and hyaline membrane was formed. ii) Diffuse alveolar hemorrhage and congestion; 0 , none; 1 , prominent congestion with extravasated blood; 2, <25\% extravasated blood; and 3, >25\% extravasated blood. iii) Intra-alveolar infiltration of inflammatory cells; 0 , none; $1,<10 \%$ aggregates; $2,10-30 \%$ aggregates; and $3,>30 \%$ aggregates. The indexes of the final score are accumulated.
ELISA. Interleukin-6 assay kit (cat. no. H007), interleukin-1 $\beta$ assay kit (cat. no. H002) and tumor necrosis factor- $\alpha$ (TNF- $\alpha$ ) assay kit (cat. no. H052) were purchased from Nanjing Jiancheng Bioengineering Institute and were used to measure IL-6, IL-1 $\beta$ and TNF- $\alpha$ levels, respectively, in the BALF according to the manufacturer's protocol.

Lung W/D weight ratio. Pulmonary edema development was assessed by the ratio of lung W/D weight. Briefly, the lung tissues were separated from the upper lobes of the left lung. After washing in saline, the tissues were weighed immediately and reweighed followed dehydration at $80^{\circ} \mathrm{C}$ for $24 \mathrm{~h}$.

Immunofluorescence. To quantitatively measure alveolar epithelial cell death, the TUNEL/propidium iodide (PI)/Hoechst 33342 assay was used. After dewaxing with xylene and a serial ethanol gradient concentration ( $100 \%$ ethanol for $3 \mathrm{~min}, 95 \%$ ethanol for $2 \mathrm{~min}, 80 \%$ ethanol for $2 \mathrm{~min}, 75 \%$ ethanol for $2 \mathrm{~min}, \mathrm{H}_{2} \mathrm{O}$ for $1 \mathrm{~min})$, the tissue sections $(4 \mu \mathrm{m})$ were incubated with $20 \mu \mathrm{g} / \mathrm{ml}$ proteinase $\mathrm{K}$ (cat. no. ST533; Beyotime Institute of Biotechnology) for $10 \mathrm{~min}$ at $37^{\circ} \mathrm{C}$. Then, the slices were treated with TUNEL-mixture (cat. no. C1088; Beyotime Institute of Biotechnology) in the dark for $1 \mathrm{~h}$ at $37^{\circ} \mathrm{C}$. After washing with PBS, $5 \mu \mathrm{g} / \mathrm{ml}$ of Antifade Mounting Medium with Hoechst 33342 and propidium iodide (PI; cat. no. P0137; Beyotime Institute of Biotechnology) were added for $2 \mathrm{~min}$ at room temperature to stain the cell nuclei and necrotic cell. Four nonoverlapping fields of view were evaluated in each tissue section. The percentage of necrosis and apoptosis was indicated by the ratio of PI-positive nuclei or TUNEL-positive nuclei to the total cell nuclei counterstaining by Hoechst 33342, respectively.

Western blot analysis. Western blotting was used to assess the expression in ERK1/2, caspase-3, Bcl-2 and Bak. Total protein was extracted from lung tissues and lysed in tissue lysis buffer (cat. no. P0013; Beyotime Institute of Biotechnology), and the concentration was measured using a bicinchoninic acid Protein Assay Kit (cat. no. P0012S; Beyotime Institute of Biotechnology). Samples containing $30 \mu \mathrm{g}$ of total protein were separated on a $12 \%$ SDS-PAGE and transferred to a polyvinylidene fluoride membrane. The membranes were blocked with QuickBlock ${ }^{\mathrm{TM}}$ blocking buffer for western blot (Beyotime Institute of Biotechnology) at $25^{\circ} \mathrm{C}$ for $10 \mathrm{~min}$, and then incubated with primary antibodies of rabbit monoclonal anti-ERK1/2 (1:1,000; cat. no. AF1051; Beyotime Institute of Biotechnology), anti-phospho-ERK1/2 (1:1,000; cat. no. AF1891; Beyotime Institute of Biotechnology) polyclonal anti-caspase-3 (1:1,000; cat. no. ab13847; Abcam), anti-Bak (1:500; cat. no. AB016; Beyotime Institute of Biotechnology) and anti-Bcl-2 (1:500; cat. no. K003505P; Beijing Solarbio Science \& Technology Co., Ltd.) overnight at $4^{\circ} \mathrm{C}$. After rinsing with TBS+Tween-20 (0.05\%) buffer (Beyotime Institute of Biotechnology), the membranes were probed with HRP-conjugated goat anti-rabbit secondary antibodies (1:2,000; cat. no. A0208; Beyotime Institute of Biotechnology) for $1 \mathrm{~h}$ at $25^{\circ} \mathrm{C}$. After incubation with an ECL plus kit (Beyotime Institute of Biotechnology) for $5 \mathrm{~min}$, the blot was visualized and semi-quantified using Image Lab 5.1 software (Bio-Rad Laboratories, Inc.). GAPDH (1:1,000; cat. no. K106389P; Beijing Solarbio Science \& Technology Co., Ltd.) was used as an internal reference. 
A
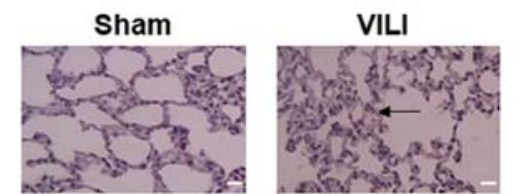
VILI+L-Dex
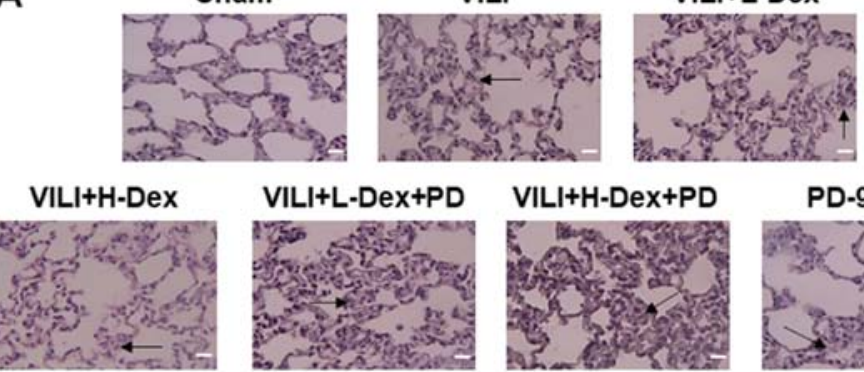

PD-98059

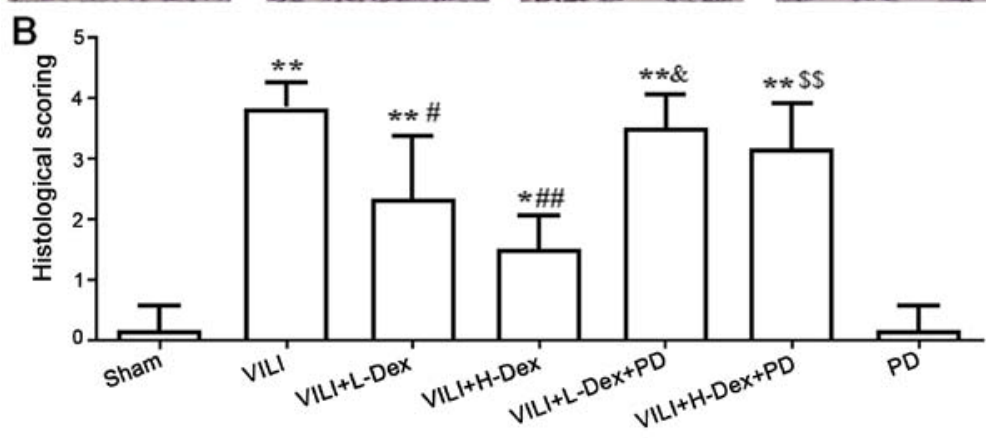

Figure 1. Dex attenuates histopathological injury in rat lungs. (A) Hematoxylin and eosin staining of rat lung tissue (magnification, $\mathrm{x} 200$; scale bar, $50 \mu \mathrm{m}$ ). The arrow indicates congestion and edema (B) The histopathological scores of degree of lung injury. Data are expressed as the mean \pm SD $(n=6)$. ${ }^{*} \mathrm{P}<0.05$, ${ }^{* *} \mathrm{P}<0.01$ vs. Sham; ${ }^{\#} \mathrm{P}<0.05,{ }^{\# /} \mathrm{P}<0.01$ vs. VILI; ${ }^{\&} \mathrm{P}<0.05$ VILI+L-Dex+PD vs. VILI+L-Dex; ${ }^{\$ \$} \mathrm{P}<0.01$ VILI+H-Dex+PD vs. VILI+H-Dex. Dex, dexmedetomidine; H-Dex, high dose Dex at $10 \mu \mathrm{g} / \mathrm{kg}$; L-Dex, low dose Dex at $1 \mu \mathrm{g} / \mathrm{kg}$; PD, PD98059; VILI, ventilator-induced lung injury.

Statistical analysis. All statistical analyses were performed using SPSS Statistics version 20.0 (IBM Corp). Data are expressed as the mean $\pm \mathrm{SD}$. When only two groups were compared, an unpaired t-test was used. Differences between more than two groups were assessed by one-way analyses of variance followed by a Bonferroni's post hoc test. $\mathrm{P}<0.05$ was considered to indicate a statistically significant difference.

\section{Results}

Dex attenuates histopathological damage in rat lungs. Lungs were stained with H\&E to assess histopathology based on morphology and scoring. The structural changes and pulmonary edema in the VILI group were more serious compared with those in the Sham group (Fig. 1). Dex treatment alleviated the lung morphologic injury, especially in the VILI+H-Dex group compared with the VILI group. However, after inhibition with PD98059, the protective effect of Dex on morphology was weakened. PD98059 injection alone did not damage the lung tissue.

Dex was demonstrated to have little effect on hemodynamics. During the treatment process, the hemodynamics of rats were found to be relatively stable (Tables SI and SII). This indicated that hemodynamics have no effect on the pathology and inflammatory response.

Dex reduces the level of inflammatory cytokines in BALF. The effects of Dex on inflammatory cytokine levels in BALF were measured using ELISAs. The results demonstrated that the production of TNF- $\alpha$, IL-1 $\beta$ and IL-6 in the VILI group were significantly increased compared with levels in the Sham group $(\mathrm{P}<0.05$; Fig. 2). L-Dex $(\mathrm{P}<0.05)$ and H-Dex $(\mathrm{P}<0.01)$ significantly downregulated the expression levels of inflammatory cytokines compared with the VILI group. PD98059 pretreatment significantly offset the effects of Dex in the VILI+L-Dex
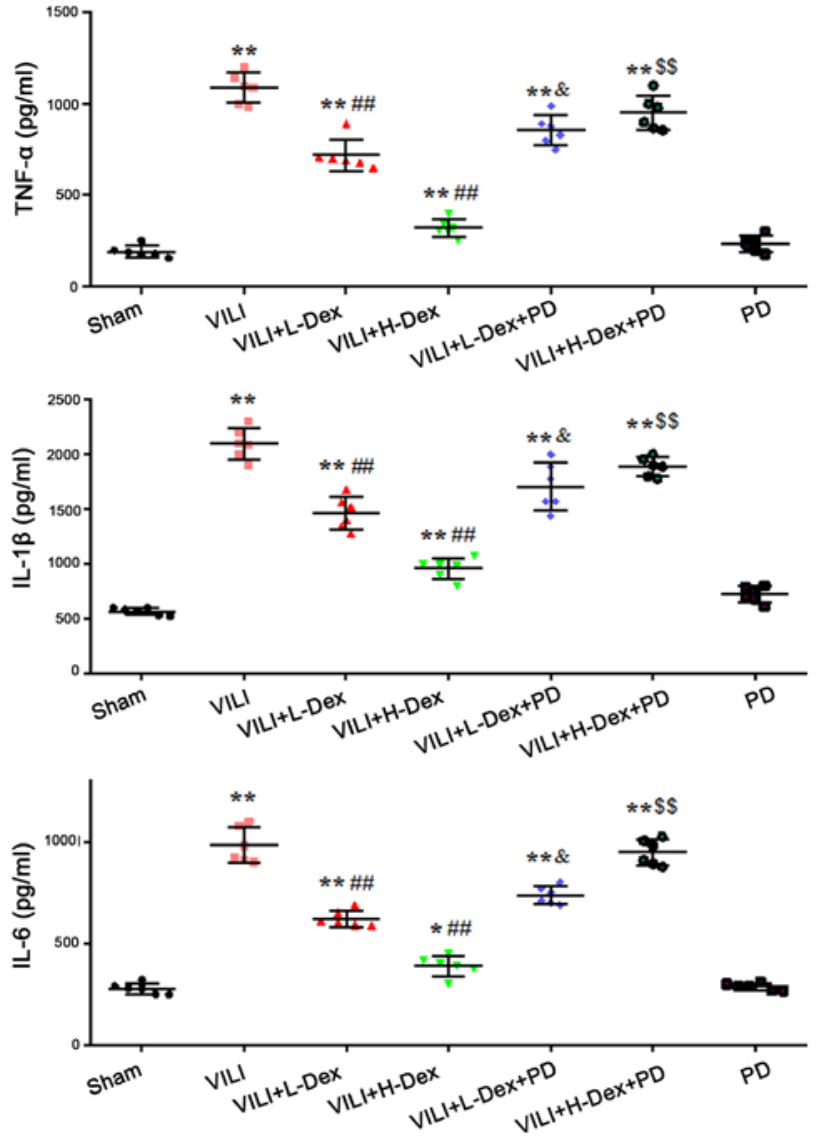

Figure 2. Dex reduces the expression levels of inflammatory cytokines in BALF. The expression levels of TNF- $\alpha$, IL- $1 \beta$ and IL- 6 in the BALF of rats. The data are expressed as the mean $\pm \mathrm{SD}(\mathrm{n}=6) .{ }^{*} \mathrm{P}<0.05,{ }^{* *} \mathrm{P}<0.01$ vs. Sham; ${ }^{\# \#} \mathrm{P}<0.01$ vs. VILI group; ${ }^{\&} \mathrm{P}<0.05$ VILI+L-Dex+PD vs. VILI+L-Dex; ${ }^{\$} \$ \mathrm{P}<0.01$ VILI+H-Dex+PD vs. VILI+H-Dex. BALF, bronchoalveolar lavage fluid; Dex, dexmedetomidine; H-Dex, high dose Dex at $10 \mu \mathrm{g} / \mathrm{kg}$; L-Dex, low dose Dex at $1 \mu \mathrm{g} / \mathrm{kg}$; PD, PD98059; VILI, ventilator-induced lung injury. 


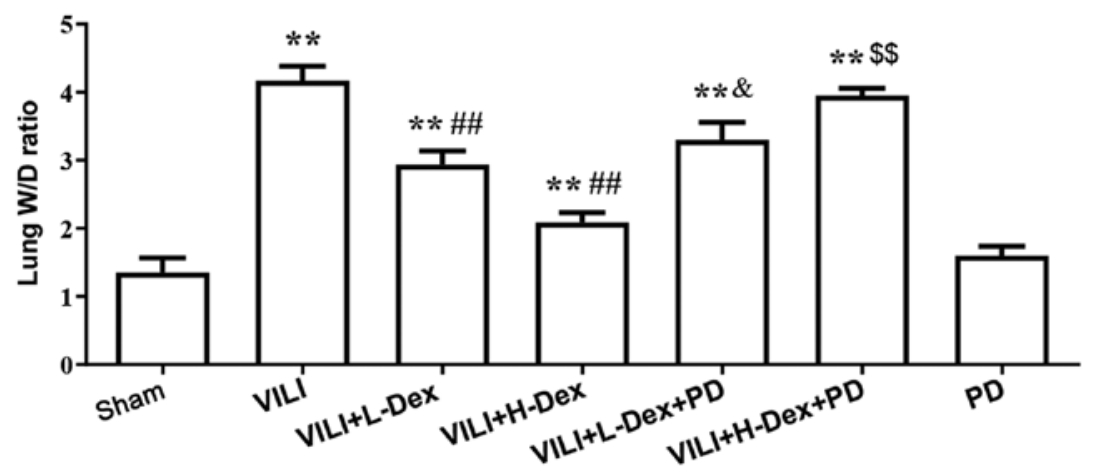

Figure 3. Dex reduces the lung W/D ratio. The values of the W/D weight ratio in different groups are presented as mean $\pm \mathrm{SD}(\mathrm{n}=6)$. ${ }^{* *} \mathrm{P}<0.01 \mathrm{vs}$. Sham; ${ }^{\# \prime} \mathrm{P}<0.01$ vs. VILI; ${ }^{\text {P}} \mathrm{P}<0.05$ VILI+L-Dex+PD vs. VILI+L-Dex; ${ }^{\text {\$ }} \mathrm{P}<0.01 \mathrm{VILI}+\mathrm{H}-\mathrm{Dex}+\mathrm{PD}$ vs VILI+H-Dex. Dex, dexmedetomidine; H-Dex, high dose Dex at $10 \mu \mathrm{g} / \mathrm{kg}$; L-Dex, low dose Dex at $1 \mu \mathrm{g} / \mathrm{kg}$; PD, PD98059; VILI, ventilator-induced lung injury; W/D, wet/dry.

A Sham

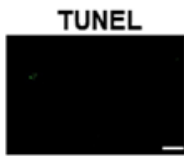

VILI
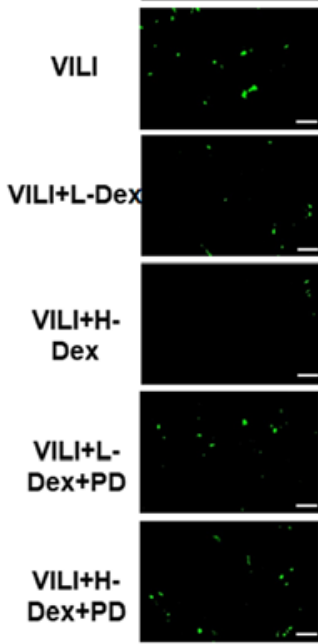

PD-98059

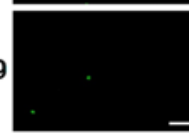

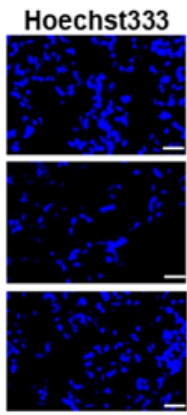
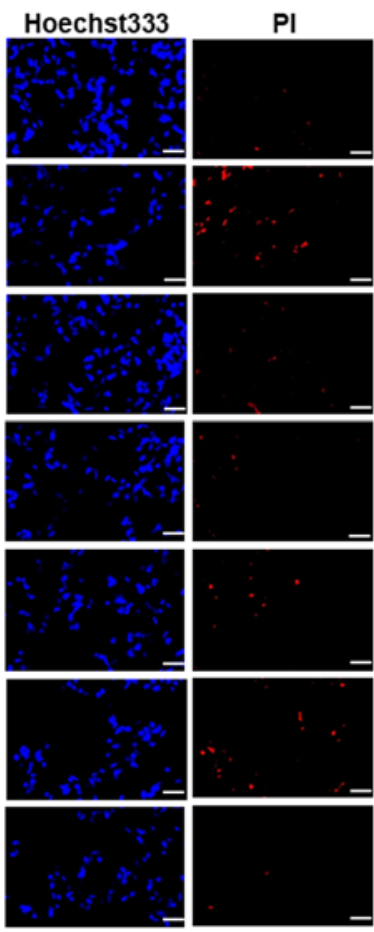

Merge
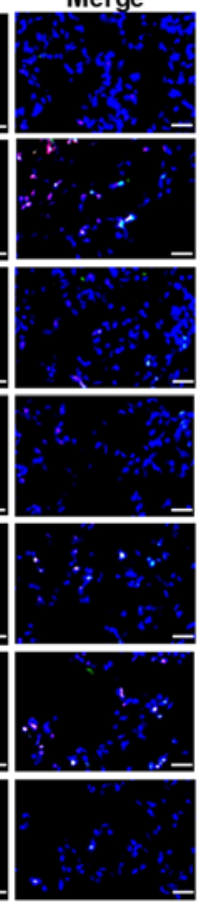

B

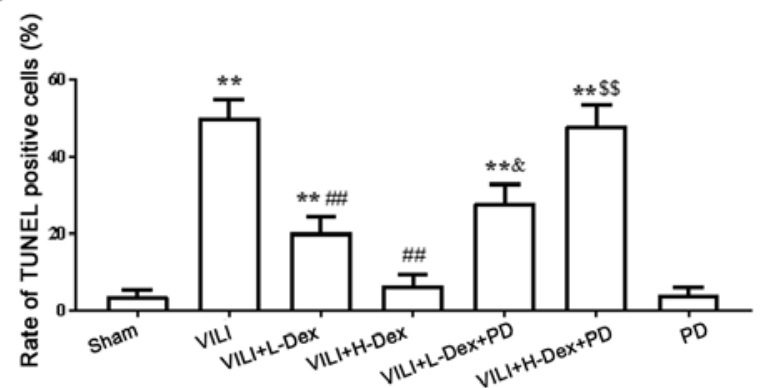

C

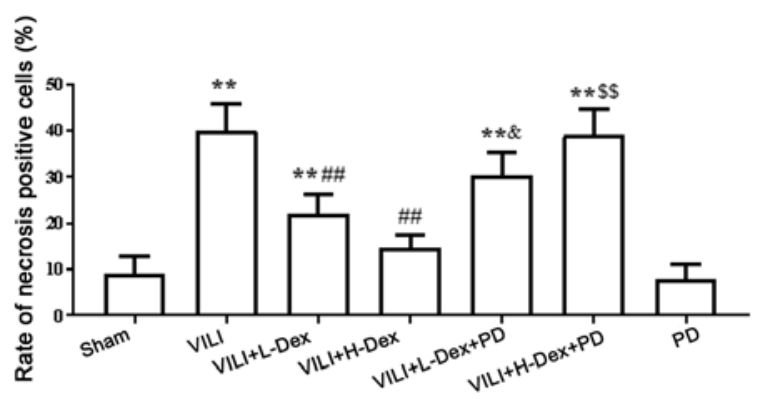

Figure 4. Dex reduces alveolar epithelial cell death. (A) PI-positive cells (red) and TUNEL-positive cells (green) were assessed by immunofluorescence staining; Hoechst 33342 (blue). Magnification, x400; scale bar, $20 \mu \mathrm{m}$. (B) Apoptosis was quantitatively observed with TUNEL staining. (C) The quantification of necrosis using PI staining in each tested group. Data are presented as the mean \pm SD ( $=6$ ). ${ }^{* *} \mathrm{P}<0.01$ vs. Sham; ${ }^{\# \#} \mathrm{P}<0.01$ vs. VILI; ${ }^{\&} \mathrm{P}<0.05$ VILI+L-Dex+PD vs. VILI+L-Dex group; ${ }^{\$} \mathrm{P}<0.01$ VILI+H-Dex+PD vs VILI+H-DexDex, dexmedetomidine; H-Dex, high dose Dex at $10 \mu \mathrm{g} / \mathrm{kg}$; L-Dex, low dose Dex at $1 \mu \mathrm{g} / \mathrm{kg}$; PD, PD98059; VILI, ventilator-induced lung injury.

and VILI+H-Dex groups, compared with the VILI+L-Dex+PD and VILI+H-Dex+PD groups (both $\mathrm{P}<0.05$; Fig. 2).

Dex reduces the lung W/D weight ratio. Pulmonary edema was evaluated by the W/D weight ratio of the lungs (Fig. 3). The W/D ratio in the VILI group was found to be significantly higher compared with that in the Sham group $(\mathrm{P}<0.05)$. In the VILI+L-Dex $(\mathrm{P}<0.05)$ and the VILI+H-Dex treatment groups $(\mathrm{P}<0.01)$, Dex significantly reduced the lung $\mathrm{W} / \mathrm{D}$ ratios compared with the VILI group. PD98059 pretreatment was found to reverse the protective effects of Dex $(\mathrm{P}<0.05)$.

Dexreduces alveolar epithelialcelldeath.Immunofluorescence assays demonstrated that, compared with the Sham group, the necrosis and apoptosis of alveolar epithelial cells significantly increased in the VILI treated group ( $\mathrm{P}<0.05$; Fig. 4). However, a significant decrease was revealed in VILI model rats treated with L-Dex or H-Dex compared with the VILI group $(\mathrm{P}<0.05$ and $\mathrm{P}<0.01$, respectively). Moreover, compared with the rats treated with VILI+H-Dex and VILI+L-Dex, there was a significant increase in cell death in the VILI+H-Dex+PD and VILI+L-Dex+PD groups, respectively ( $\mathrm{P}<0.05$ for both; Fig. 4). Additionally, there was no significant difference in cell death between the Sham group and the PD group.

Dex may inhibit alveolar epithelial cell apoptosis and decrease the Bak/Bcl-2 ratio via ERK1/2 activation. To further understand the mechanism of Dex on cell death, 


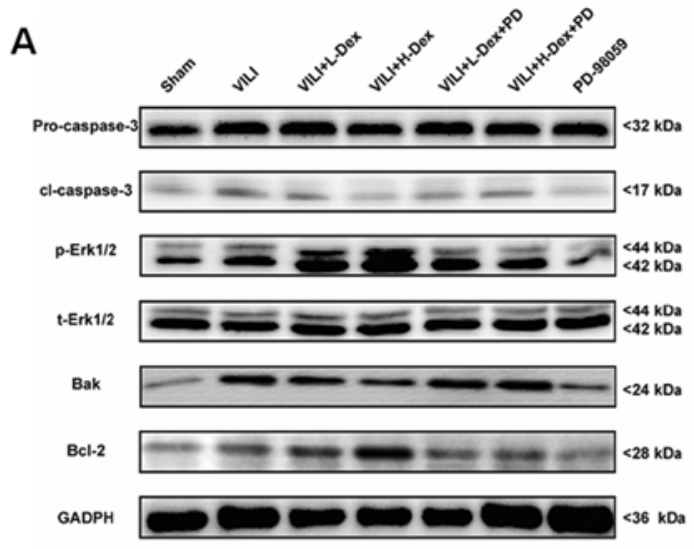

C

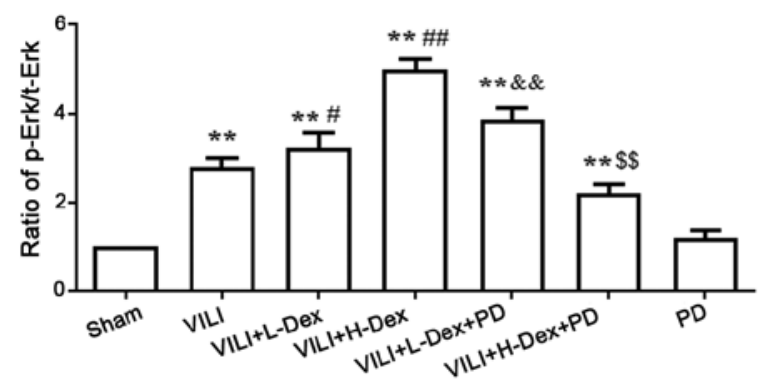

B

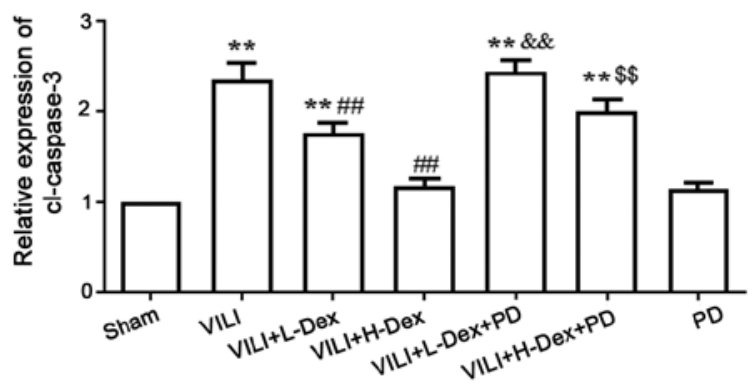

D

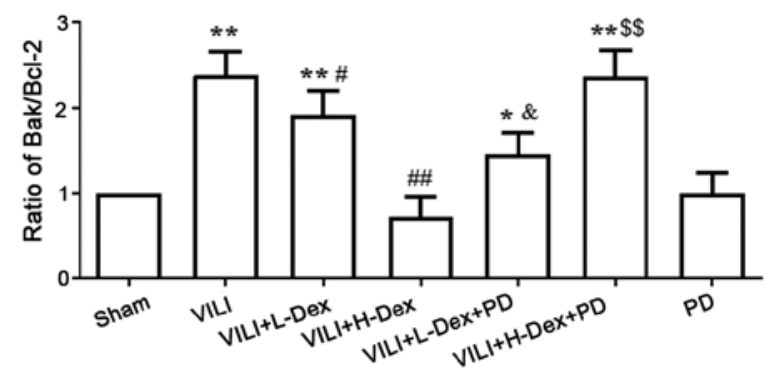

Figure 5. Dex may inhibit alveolar epithelial cell apoptosis and decrease the Bak/Bcl-2 ratio through ERK1/2 activation. (A) Representative western blotting images of pro- and cl-caspase-3, p-ERK1/2, t-ERK1/2, Bak and Bcl-2 in the lung. The semi-quantified protein expression level of (B) cl-caspase-3, (C) p-ERK/t-ERK and (D) Bak/Bcl-2. Data are presented as the mean $\pm \mathrm{SD}(\mathrm{n}=6) .{ }^{*} \mathrm{P}<0.05,{ }^{* *} \mathrm{P}<0.01$ vs. Sham; ${ }^{*} \mathrm{P}<0.05,{ }^{\# \#} \mathrm{P}<0.01$ vs. VILI; ${ }^{\text {\& }} \mathrm{P}<0.05$, \&\& $\mathrm{P}<0.01$ VILI+L-Dex+PD vs. VILI+L-Dex group; ${ }^{\$ \$} \mathrm{P}<0.01 \mathrm{VILI}+\mathrm{H}-\mathrm{Dex}+\mathrm{PD}$ vs VILI+H-Dex. Cl, cleaved; Dex, dexmedetomidine; H-Dex, high dose Dex at $10 \mu \mathrm{g} / \mathrm{kg}$; L-Dex, low dose Dex at $1 \mu \mathrm{g} / \mathrm{kg}$; p-, phosphorylated; PD, PD98059; t-, total; VILI, ventilator-induced lung injury.

the protein expression levels of Bak, Bcl-2, pro-caspase-3 and cleaved caspase- 3 in the lung tissues were detected by western blotting (Fig. 5). The expression levels of Bak/Bcl-2 and cleaved caspase- 3 significantly increased in the VILI, VILI+L-Dex, VILI+H-Dex, VILI+L-Dex+PD and VILI+H-Dex+PD groups compared with the Sham group $(\mathrm{P}<0.05$; Fig. 5), whereas compared with the VILI group, L-Dex and H-Dex significantly reduced the expression levels of apoptotic proteins Bak/Bcl-2 and cleaved caspase-3. PD98059 co-treatment largely reversed the Bak/Bcl-2 and cleaved caspase- 3 in the VILI+L-Dex+PD and VILI+H-Dex+PD groups compared with VILI+L-Dex and VILI+H-Dex. Moreover, there was no difference in pro-caspase-3 expression in each group.

To investigate whether the antiapoptotic and anti-inflammatory effects of Dex were associated with the ERK1/2 pathway, PD98059 was administered prior to Dex treatment. Western blot analysis showed that the ratio of p-ERK/total (t)-ERK (which included phosphorylated and dephosphorylated ERK) significantly increased in VILI model rats compared with those in the Sham group $(\mathrm{P}<0.05$; Fig. $5 \mathrm{C})$. However, further analysis of the results indicated that the p-ERK/t-ERK ratio was significantly higher in the VILI+L-Dex and VILI+H-Dex group compared with the VILI group $(\mathrm{P}<0.05$ and $\mathrm{P}<0.01$, respectively; Fig. 5C). PD98059 co-treatment largely reversed the p-ERK/t-ERK ratio in the VILI+L-Dex+PD and VILI+H-Dex+PD group compared with VILI+L-Dex and VILI+H-Dex, respectively (both $\mathrm{P}<0.05$; Fig. 5C).

\section{Discussion}

MV is a life-saving therapy for ARDS and patients with acute respiratory failure, such as acute lung injury, and is critical in general anesthesia (12). However, excessive ventilation can exacerbate pre-existing lung damage and damage healthy lungs, this process is known as VILI $(22,23)$. The mechanisms of VILI involve atelectrauma, barotrauma, biotrauma and volutrauma (24), although there are numerous factors that have been considered as possible triggers for VILI. Based on a previous study (20), a rat VILI model using the HVT-MV method was successfully established in the present study.

Dex has a high affinity for $\alpha 2$ adrenoceptor and it is widely used in critically ill patients (at $1-1.5 \mu \mathrm{g} / \mathrm{kg} / \mathrm{h}$ ) owing to its sedative effects without respiratory inhibition $(25,26)$. Numerous studies have also reported the anti-inflammatory effects of Dex by reducing the expression of inflammatory factors in certain specific cases (27-29). Considering previous literature reports and clinical dose analysis $(11,12)$, two doses of Dex were examined in the present study. The data showed that high doses of Dex at $10 \mu \mathrm{g} / \mathrm{kg} / \mathrm{h}$ significantly decreased expression of the inflammation-related cytokines IL-1 $\beta$, IL-6 and TNF- $\alpha$, W/D ratios and pathological changes in the VILI model rats. Several reports have demonstrated that Dex reduces the apoptosis of various parenchymal and epithelial cells following inflammation or ischemia (30-33). Similarly, H-Dex was found to significantly reduce alveolar epithelial cell apoptosis. The present results suggested that Dex may 
reduce lung injury via suppressing inflammatory responses and cell death. These protective effects may, in part, be due to $\alpha 2$ adrenoceptors.

In the present study, p-ERK1/2 expression was significantly increased in the lung tissue exposed to VILI or VILI+Dex. Moreover, Dex pretreatment appeared to induce more phosphorylation of ERK1/2. In addition, VILI treatment was demonstrated to induce a significant increase in cell death, whereas Dex pretreatment helped to attenuate these effects. However, when the phosphorylation of ERK1/2 was inhibited by PD98059, the protective effects of Dex appeared to be largely weakened. The neuroprotective role of Dex against cerebral ischemic injury may function via phosphorylation of ERK1/2 or the MAPK/ERK pathway $(34,35)$. Similarly, the present study indicated that Dex pretreatment may protect alveolar epithelial cells against VILI-mediated effects through ERK1/2 activation.

A previous study has demonstrated that the activation of ERK1/2 may inhibit the NF- $\kappa \mathrm{B}$ signaling pathway, which results in a reduction in the expression levels of inflammatory factors (for example, IL-1 $\beta$, IL- 6 and TNF- $\alpha$ ) and apoptotic proteins, such as caspase- 3 and $\mathrm{Bak}$, thereby reducing hypoxia-induced damage (36). The present study results indicated that Dex reduced the expression levels of Bak, Bcl-2 and cleaved caspase-3, and decreases the secretion of inflammatory cytokines. However, these protective effects also partially following with the administration of PD98059. It has also been reported that activation of the ERK1/2 signal pathway may regulate the expression of aquaporins (37), in the present study, Dex reduced the ratio of W/D lung tissue weight, possibly by regulating the expression of aquaporins and activating ERK1/2. A study that compared the gene expression characteristics of lung injury in rodents and humans have found that conserved pathways, including MEK1/2-ERK1/2, are potential targets against the injury pathway (38). The MEK1/2-ERK1/2 pathway has an important role in inflammatory responses. It can be stimulated by signals downstream of Ras and Raf, and extracellular stimuli, such as growth factors and cytokines (39). PD98059 binds inactive enzymes of MEK1 and MEK2, which prevents their activation by Raf kinase, thereby inhibiting ERK1/2 activation (40). U0126 is known to directly inhibit the catalytic activity of active MEK1 and block MEK1/2 activity; U0126 primarily inhibits the phosphorylation of ERK (41). This study focused on ERK1/2 in the MEK/ERK pathway and demonstrated that PD98059 had a greater effect compared with U0126 in preliminary experiments, thus, PD98059 was chosen as an upstream inhibitor in this study.

In summary, the present study emphasized the protective effects of Dex against VILI and the role of Dex in the treatment of VILI. However, this study was still in its preliminary stage and further in vitro and in vivo studies of molecular mechanisms and signaling pathways are necessary to confirm these results.

\section{Acknowledgements}

Not applicable.

\section{Funding}

No funding was received.

\section{Availability of data and materials}

All data generated or analyzed during this study are included in this published article.

\section{Authors' contributions}

CHZ and SQS conceptualized the study. CHZ, JY, BQW, YN, LW and SQS performed the experiments and collected the data. CHZ and JY analyzed the data. All authors read and approved the final manuscript.

\section{Ethics approval and consent to participate}

All study procedures and animal handling were approved by the Animal Review Board of Cangzhou Central Hospital (Cangzhou, China; approval no. 2015-009-01).

\section{Patient consent for publication}

Not applicable.

\section{Competing interests}

The authors declare that they have no competing interests.

\section{References}

1. Ball L, Dameri M and Pelosi P: Modes of mechanical ventilation for the operating room. In: Best Practice and Research Clinical Anaesthesiology. Vol 29. Elsevier, Amsterdam, pp285-299, 2015.

2. Hartmann EK, Boehme S, Bentley A, Duenges B, Klein KU, Elsaesser A, Baumgardner JE, David M and Markstaller K: Influence of respiratory rate and end-expiratory pressure variation on cyclic alveolar recruitment in an experimental lung injury model. Crit Care 16: R8, 2012.

3. Rocco PR, Dos Santos C and Pelosi P: Pathophysiology of ventilator-associated lung injury. Curr Opin Anaesthesiol 25: 123-130, 2012.

4. Usatyuk PV and Natarajan V: Hydroxyalkenals and oxidized phospholipids modulation of endothelial cytoskeleton, focal adhesion and adherens junction proteins in regulating endothelial barrier function. Microvasc Res 83: 45-55, 2012.

5. Frank JA, Parsons PE and Matthay MA: Pathogenetic significance of biological markers of ventilator-associated lung injury in experimental and clinical studies. Chest 130: 1906-1914, 2006.

6. Scheiermann J and Klinman DM: Suppressive oligonucleotides inhibit inflammation in a murine model of mechanical ventilator induced lung injury. J Thorac Dis 8: 2434-2443, 2016.

7. Ko YA, Yang MC, Huang HT, Hsu CM and Chen LW: NF-кB activation in myeloid cells mediates ventilator-induced lung injury. Respir Res 14: 69, 2013.

8. Dent BT, Aarnes TK, Wavreille VA, Lakritz J, Lerche P, KuKanich B, Riccó Pereira CH and Bednarski RM: Pharmacokinetics and pharmacodynamic effects of oral transmucosal and intravenous administration of dexmedetomidine in dogs. Am J Vet Res 80: 969-975, 2019.

9. Ma D, Hossain M, Rajakumaraswamy N, Arshad M, Sanders RD, Franks NP and Maze M: Dexmedetomidine produces its neuroprotective effect via the alpha 2A-adrenoceptor subtype. Eur J Pharmacol 502: 87-97, 2004.

10. Taniguchi T, Kurita A, Kobayashi K, Yamamoto K and Inaba H: Dose- and time-related effects of dexmedetomidine on mortality and inflammatory responses to endotoxin-induced shock in rats. J Anesth 22: 221-228, 2008.

11. Chen C, Zhang Z, Chen K, Zhang F, Peng M and Wang Y: Dexmedetomidine regulates inflammatory molecules contributing to ventilator-induced lung injury in dogs. J Surg Res 187: 211-218, 2014. 
12. Chen H, Sun X, Yang X, Hou Y, Yu X, Wang Y, Wu J, Liu D, Wang $\mathrm{H}$, Yu J, et al: Dexmedetomidine reduces ventilatorinduced lung injury (VILI) by inhibiting Toll-like receptor 4 (TLR4)/nuclear factor (NF)- $\mathrm{BB}$ signaling pathway. Bosn J Basic Med Sci 18: 162-169, 2018.

13. Johnson GL and Lapadat R: Mitogen-activated protein kinase pathways mediated by ERK, JNK, and p38 protein kinases. Science 298: 1911-1912, 2002.

14. Gong G, Yuan L, Cai L, Ran M, Zhang Y, Gong H, Dai X, Wu W and Dong H: Tetramethylpyrazine suppresses transient oxygenglucose deprivation-induced connexin32 expression and cell apoptosis via the ERK1/2 and p38 MAPK pathway in cultured hippocampal neurons. PLoS One 9: e105944, 2014.

15. Zhang L, Jiang B, Zhu N, Tao M, Jun Y, Chen X, Wang Q and Luo C: Mitotic checkpoint kinase Mps1/TTK predicts prognosis of colon cancer patients and regulates tumor proliferation and differentiation via PKC $\alpha /$ ERK $1 / 2$ and PI3K/Akt pathway. Med Oncol 37: 5, 2019.

16. Long ME, Gong KQ, Eddy WE, Volk JS, Morrell ED, Mikacenic C, West TE, Skerrett SJ, Charron J, Liles WC, et al: MEK1 regulates pulmonary macrophage inflammatory responses and resolution of acute lung injury. JCI Insight 4: e132377, 2019.

17. Goyagi $\mathrm{T}$ and Tobe Y: Dexmedetomidine improves the histological and neurological outcomes $48 \mathrm{~h}$ after transient spinal ischemia in rats. Brain Res 1566: 24-30, 2014.

18. Sanders RD, Giombini M, Ma D, Ohashi Y, Hossain M, Fujinaga $M$ and Maze M: Dexmedetomidine exerts dosedependent age-independent antinociception but age-dependent hypnosis in Fischer rats. Anesth Analg 100: 1295-1302, 2005

19. Gao Y, Zhou S, Wang F, Zhou Y, Sheng S, Qi D, Huang JH, Wu E, Lv Y and Huo X: Hepatoprotective effects of limb ischemic post-conditioning in hepatic ischemic rat model and liver cancer patients via PI3K/ERK pathways. Int J Biol Sci 14: 2037-2050, 2018.

20. Li LF, Liao SK, Ko YS, Lee CH and Quinn DA: Hyperoxia increases ventilator-induced lung injury via mitogen-activated protein kinases: A prospective, controlled animal experiment. Crit Care 11: R25, 2007.

21. Sammons MJ, Raval P, Davey PT, Rogers D, Parsons AA and Bingham S: Carrageenan-induced thermal hyperalgesia in the mouse: Role of nerve growth factor and the mitogen-activated protein kinase pathway. Brain Res 876: 48-54, 2000.

22. Biehl M, Kashiouris MG and Gajic O: Ventilator-induced lung injury: Minimizing its impact in patients with or at risk for ARDS. Respir Care 58: 927-937, 2013.

23. Cortjens B, Royakkers AA, Determann RM, van Suijlen JD, Kamphuis SS, Foppen J, de Boer A, Wieland CW, Spronk PE, Schultz MJ, et al: Lung-protective mechanical ventilation does not protect against acute kidney injury in patients without lung injury at onset of mechanical ventilation. J Crit Care 27: 261-267, 2012.

24. Ye L, Zeng Q, Dai H, Zhang W, Wang X, Ma R, Hong X, Zhao C and Pan L: Endoplasmic reticulum stress is involved in ventilatorinduced lung injury in mice via the IRE1 $\alpha-T R A F 2-N F-\kappa B$ pathway. Int Immunopharmacol 78: 106069, 2020.

25. Cruickshank M, Henderson L, MacLennan G, Fraser C, Campbell M, Blackwood B, Gordon A and Brazzelli M Alpha-2 agonists for sedation of mechanically ventilated adults in intensive care units: a systematic review. Health Technol Assess 20: v-xx, 1-117, 2016.

26. Shehabi Y, Howe BD, Bellomo R, Arabi YM, Bailey M, Bass FE, Bin Kadiman S, McArthur CJ, Murray L, Reade MC, et al; ANZICS Clinical Trials Group and the SPICE III investigators: Early sedation with dexmedetomidine in critically ill patients. N Engl J Med 380: 2506-2517, 2019.
27. Gao J, Sun Z, Xiao Z, Du Q, Niu X, Wang G, Chang YW, Sun Y, Sun W, Lin A, et al: Dexmedetomidine modulates neuroinflammation and improves outcome via alpha2-adrenergic receptor signaling after rat spinal cord injury. Br J Anaesth 123: 827-838, 2019.

28. Cheng F, Yan FF, Liu YP, Cong Y, Sun KF and He XM: Dexmedetomidine inhibits the NF- $\mathrm{B}$ pathway and NLRP3 inflammasome to attenuate papain-induced osteoarthritis in rats. Pharm Biol 57: 649-659, 2019.

29. Zhou XY, Liu J, Xu ZP, Fu Q, Wang PQ and Zhang HA: Dexmedetomidine inhibits the lipopolysaccharide-stimulated inflammatory response in microglia through the pathway involving TLR4 and NF-кB. Kaohsiung J Med Sci 35: 750-756, 2019.

30. Xie Y, Guo C, Liu Y, Shi L and Yu J: Dexmedetomidine activates the PI3K/Akt pathway to inhibit hepatocyte apoptosis in rats with obstructive jaundice. Exp Ther Med 18: 4461-4466, 2019.

31. Zhai M, Liu C, Li Y, Zhang P, Yu Z, Zhu H, Zhang L, Zhang Q, Wang J and Wang J: Dexmedetomidine inhibits neuronal apoptosis by inducing Sigma-1 receptor signaling in cerebral ischemiareperfusion injury. Aging (Albany NY) 11: 9556-9568, 2019

32. Sun J,Zheng S, Yang N, Chen B, He G and Zhu T: Dexmedetomidine inhibits apoptosis and expression of COX-2 induced by lipopolysaccharide in primary human alveolar epithelial type 2 cells. Biochem Biophys Res Commun 517: 89-95, 2019.

33. Cui J, Zhao H, Wang C, Sun JJ, Lu K and Ma D: Dexmedetomidine attenuates oxidative stress induced lung alveolar epithelial cell apoptosis in vitro. Oxid Med Cell Longev 2015: 358396, 2015.

34. Shi Y, Peng XH, Li X, Luo GP and Wu MF: Neuroprotective role of dexmedetomidine pretreatment in cerebral ischemia injury via ADRA2A-mediated phosphorylation of ERK1/2 in adult rats. Exp Ther Med 16: 5201-5209, 2018.

35. Qiu Z, Lu P, Wang K, Zhao X, Li Q, Wen J, Zhang H, Li R, Wei H, Lv Y, et al: Dexmedetomidine inhibits neuroinflammation by altering microglial M1/M2 polarization through MAPK/ERK pathway. Neurochem Res 45: 345-353, 2020.

36. Jin $\mathrm{H}$ and $\mathrm{Yu}$ J: Lidocaine protects $\mathrm{H} 9 \mathrm{c} 2$ cells from hypoxiainduced injury through regulation of the MAPK/ERK/NF- $\kappa B$ signaling pathway. Exp Ther Med 18: 4125-4131, 2019.

37. Shen Q, Ma X, Hua Y, Chen M, Wang Y, Zhou Q, Ye W and Zhu X: Aquaporin 3 expression induced by salvia miltiorrhiza via ERK1/2 signal pathway in the primary human amnion epithelium cells from isolated oligohydramnios. Curr Mol Med 16: 312-319, 2016.

38. Sweeney TE, Lofgren S, Khatri P and Rogers AJ: Gene expression analysis to assess the relevance of rodent models to human lung injury. Am J Respir Cell Mol Biol 57: 184-192, 2017.

39. Caunt CJ, Sale MJ, Smith PD and Cook SJ: MEK1 and MEK2 inhibitors and cancer therapy: The long and winding road. Nat Rev Cancer 15: 577-592, 2015.

40. Dudley DT, Pang L, Decker SJ, Bridges AJ and Saltiel AR: A synthetic inhibitor of the mitogen-activated protein kinase cascade. Proc Natl Acad Sci USA 92: 7686-7689, 1995.

41. Chen Y, Zhang H, Liu E, Xu CB and Zhang Y: Homocysteine regulates endothelin type $\mathrm{B}$ receptors in vascular smooth muscle cells. Vascul Pharmacol 87: 100-109, 2016.

This work is licensed under a Creative Commons Attribution-NonCommercial-NoDerivatives 4.0 International (CC BY-NC-ND 4.0) License. 